\title{
Introduction: \\ Why We Need an Analytical Sociological Theory
}

\author{
José A. Noguera
}

Universitat Autònoma de Barcelona. Departament de Sociologia

08193 Bellaterra (Barcelona). Spain

jose.noguera@uab.es

\begin{abstract}
Sociology has long lived in a stigmatized and pre-paradigmatic state that is highly counterproductive for its status as a scientific discipline. Analytical Sociological Theory (AST) constitutes an attempt to change that situation by clarifying sociological concepts and practices, as well as optimizing and systematizing good explanatory work in social sciences. This essay presents some basic epistemic and methodological principles of AST and discusses their implications for traditional or "pre-analytical» ways of understanding social science. Its main aim is to serve as an introduction to the articles on AST that are compiled in this issue of Papers.
\end{abstract}

Key words: analytical sociology, sociological theory, epistemology, methodology, explanation, formalization, reductionism, unity of science.

\section{Resumen. Introducción: por qué necesitamos una teoría sociológica analitica}

La sociología ha vivido durante largo tiempo en un estado estigmatizado y pre-paradigmático que resulta altamente contraproducente para su status como disciplina científica. La Teoría Sociológica Analítica (TSA) constituye un intento de cambiar esa situación, introduciendo un cierto orden en los conceptos y prácticas sociológicas, y optimizando y sistematizando el buen trabajo de explicación en las ciencias sociales. Este texto presenta algunos supuestos epistémicos y metodológicos básicos de la TSA y discute sus implicaciones para las maneras tradicionales o "pre-analíticas» de entender la ciencia social. Su principal objetivo es servir como introducción a los artículos sobre la TSA reunidos en este número monográfico de Papers.

Palabras clave: sociología analítica, teoría sociológica, epistemología, metodología, explicación, formalización, reduccionismo, unidad de la ciencia.

\section{Contents}

1. The alternative of Analytical Sociological Theory

2. Some epistemic and methodological principles of AST

3. The articles in this issue
Acknowledgements

Basic and introductory texts on Analytical Sociological Theory

References 
For anyone who wants to promote truth and enlightenment it is a necessity and even a duty to train himself in the art of expressing things clearly and unambiguously - even if this means giving up certain niceties of metaphor and clever double meanings.

Karl Popper (1940: 322)

We all know that words are multimeaning, that our concepts are conceived very differently, and that our arguments are plagued by ambiguities and inconsistencies. The point is what to do about all of this. Can the present-day chaos be turned into a cosmos that allows, at a minimum, for intelligible communication and constructive discussion? We believe so, and we attempt to show how this can be done.

Giovanni Sartori (1984: 10)

Being surrounded with every conceivable kind of revolt from infancy, Gabriel had to revolt into something, so he revolted into the only thing left- sanity.

G. K. Chesterton, The Man Who Was Thursday (1908)

\section{The alternative of Analytical Sociological Theory}

Like Chesterton's Gabriel Syme, sociology has been "surrounded with every conceivable kind of revolt» since it was born. Just like him, it has arrived to the point in which the most revolutionary and critical thing would be to appeal to "sanity»: that is, to engage in the conventional procedures that may integrate it, as just another discipline, in the set of contemporary sciences, to overcome the romantic impulse to feel «special», «different», or «rebellious», and to stop denying any kind of standard and self-discipline in the name of the free expression of an allegedly irreducible subjectivity.

The long-lasting puberty of sociology as a scientific discipline has not come without cost. As Philippe Van Parijs (1981: xi-xiii) warned in one of the best (and little known) books in epistemology of the social sciences, the state of these sciences (with exceptions) may be described as stigmatized (with low social status and low self confidence) and pre-paradigmatic (lacking any standard ways of carrying out their work, or at least not recognized as such by most of the scientific community). In addition, both factors have reinforced each other: pre-paradigmatic confusion increases the stigma of a discipline while the latter hinders or inhibits the emergence of a unified paradigm ${ }^{1}$. This situation (and this is one of the main proposals of Analytical Sociological Theory) is not an epistemological necessity; it is not written in the «nature» of the social

1. See also, on this point, Goldthorpe (2000). 
sciences nor in that of its object. It is, on the contrary, an intellectual, institutional and historical option, and few would deny today that this option has proved to be counter-productive for the progress of the scientific knowledge of social phenomena.

It is worth, however, clarifying the matter. There is no doubt that a considerable part of the practical work of social scientists has satisfied and satisfies the rigourous standards of science, but often this work coexists with widespread practices and discourses that pass as «social science» while ignoring (even openly and brazenly) such standards. Even worse, good practices often get tainted, concealed or disguized under a series of blinds that pass as «social theory», and that hinder a clear and explicit appreciation of the good work that can be done and is being done in social science.

Analytical Sociological Theory (hereinafter, AST) is one of the trends that has attracted most attention on the part of social scientists over the past years. It constitutes an attempt to clarify concepts and practices, and to optimize and systematize good social-scientific work. It aims explicitly at paradigm unification in the social sciences, and at their integration with the rest of the contemporary scientific disciplines. What is AST and why do we need it? The articles in this issue try to give a detailed answer to these questions; here, I will limit myself to dealing with some principles of AST, which have important consequences for traditional or "pre-analytical» ways of understanding social science.

The adjective "analytical» refers to the separation of the elements of a "whole» to study how they make it up. As Hedström says, "'analytical sociology' seeks to explain complex social processes by carefully dissecting them and then bringing into focus their most important constituent components" (Hedström, 2005: 1). Obviously, this denomination also implies an intellectual link with the tradition of analytical philosophy, which took the logical analysis of language as its core task ${ }^{2}$. Nevertheless, to be precise, we should say that the principles of today's AST are less inspired by classical analytical philosophy than by the so-called post-analytical philosophy initiated by Quine and the «second» Wittgenstein. This philosophical trend is characterized, among other things, by the abandonment of logical atomism and of the epistemological naivety of classical analytical views (such as those of the Vienna Circle), and by the adoption of a pragmatic conception of meaning and rationality ${ }^{3}$. But

2. The uses of this tradition in the social sciences can be found mainly in economics, somewhat less in psychology and in political science, and very rarely in sociology and anthropology. This is, perhaps, the origin of the confusion or prejudice hold by many sociologists who accuse analytical sociology of being «economistic» (or, some times, "psychologistic»).

3. Between the 60's and the 80's of the 20th century, the work of Arthur C. Danto, Donald Davidson, Michael Dummett, Nelson Goodman, Ian Hacking, Thomas Nagel, Derek Parfit, Hilary Putnam, Richard Rorty, John Searle, Wilfried Sellars, and others shows this post-analytical move (D’Agostini, 1997). For the social sciences and social theory, there is a vast unexplored potential in the work of all these authors in such fields as philosophy of language, philosophy of mind, action theory, cognitive science, the theory of rationality, the theory of meaning or the theory of intentionality. 
perhaps more importantly, and just like post-analytical philosophy, AST conserves and cultivates the best of the analytical «style»: meticulous logical and conceptual work, subtle and well articulated distinctions, patience when developing an argument (ensuring and explaining every step in it), an anti-heroic and anti-exhibitionist conception of intellectual work, a preference for brief articles that deal with a specific question in detail, the use of formal models, and permanent attention to the congruence with scientific knowledge available in other disciplines.

As «classic» authors of this current in sociological theory we should mention Raymond Boudon, James S. Coleman, and Jon Elster (along with the group of «analytical Marxists» of the 80's). Economists such as Albert O. Hirschman, Mancur Olson, and Thomas Schelling have also contributed, along with the aforementioned, to sowing the seeds of contemporary analytical sociology on the fertile field developed by authors such as Peter Abell, Filippo Barbera, Diego Gambetta, John H. Goldthorpe, Michael Hechter, Douglas Heckathorn, Peter Hedström, Hartmurt Hesser, Siegwart Lindenberg, KarlDieter Opp, Richard Swedberg, A. L. Stinchcombe, and Axel van den Berg, among others. A body of work based on very similar premises and/or coming from disciplines neighbouring on sociology has been developed by Samuel Bowles, Herbert Gintis, Robert Axelrod, Michael Taylor, Edna Ullman-Margalit, Russell Hardin, Elinor Ostrom, and Erik Olin Wright. Analytical social philosophy and social ontology have been well cultivated by Margaret Gilbert, Erik Lagerspetz, Philip Pettit, John R. Searle, Raimo Tuomela, and others. And in the Spanish context, many authors base their research on all or some of these contributions and try to work along the same lines, like for example, Fernando Aguiar, Andrés de Francisco, Antoni Domènech, Sandra González, Francisco Herreros, Francisco Linares, Ángeles Lizón, Luis Miguel Miller, Jordi Mundó, Félix Ovejero, Daniel Raventós, and Ignacio Sánchez-Cuenca, to name just a few.

A question on terminology: should we speak of «analytical social theory», of "analytical sociological theory", or of "analytical sociology»? The last two expressions seem to be the most accepted ones in recent years ${ }^{4}$. And it is true that the expression "social theory» is often used to designate precisely those discourses that analytical authors despise as vague, empty or centred on pseudo-questions such as "overcoming theoretical dilemmas» or the creation of mere "conceptual labels» to rename well-known phenomena. Even accepting to a large extent this diagnosis, there are two motives for leaving the door open to the expression «analytical social theory»: a) In the first place, this expression also includes the work of many social and behavioural scientists (psychologists, economists, political scientists, anthropologists, biologists) who work along analytical lines, and some of whom share with analytical sociolo-

4. Although the subtitle of the reference book compiled by Hedström and Swedberg, Social Mechanisms (1998), was An Analytical Approach to Social Theory. 
gists much more than they do with some colleagues from their own discipline. b) Second, the term «social theory» could also cover those (abovementioned) authors who work in analytical social ontology (see, for example, Searle's article in this issue), or in the rigorous production of concepts, definitions or formal models that can be relevant and useful for the social sciences.

In any case, we should point out that the mere fact of speaking of "analytical sociological (or social) theory» is a symptom of the pre-paradigmatic situation of most of the social sciences, given that AST is not so much a «substantive» theoretical orientation as rather a "way of doing things» that seeks to turn sociology into an informative and fertile scientific discipline. In an «ideal» situation, therefore, AST would be the sociological scientific kind of theory per se.

Having made these prior clarifications, in the rest of the essay I review some of the main epistemic and methodological principles of AST, and then I briefly introduce the articles that make up this issue.

\section{Some epistemic and methodological principles of AST}

\subsection{Realism and objectivity}

\section{Realism}

AST, even assuming all the epistemological sophistication of post-analytical philosophy and avoiding positivist naivety, is not at all in favour of playing at relativism or unrealism in any of its variants, no matter how many "nuances» may be introduced. On the contrary, it shares the "common sense» view that there is an objective causal world which exists independently of human agreement $^{5}$, and that this world, be it natural or social, is knowable and intelligible in a reliable and objective (although approximate and fallible) way by means of a series of logical, conceptual and technical tools used in the context of the institutionalized procedures of modern science. This stance does not mean that AST ignores the complex questions that underlie the ontology and epistemology of social phenomena (Searle, 1995; Hedström, 2005; Goldthorpe, 2000), but these questions do not lead AST to fall into any sort of empty linguistic idealism nor a trivial social constructionism (Hacking, 1999; Domènech, 2005; Boudon, 2004).

\section{Objectivity}

It is very frequently assumed that objectivity is impossible (and even undesirable) in sociology, on the basis of one or more of the following reasons: a) The "procedural» character of social reality entails that it cannot be studied as a "given» or as a «fixed» reality. This triviality is the same as confusing the soup (that is also a "procedural» reality) with a chemical analysis of the soup.

5. In the case of institutional reality, as Searle well points out (1995), this independence is epistemic, not ontological. See his article in this issue. 
Of course, any scientific study of an object must «abstract» and "fix» it relative to the course of events, in the same way that a map "fixes» a territory, but this does not rule out the objectivity of the map. $b$ ) The «reflexivity» of the social scientist, who as a member of society is part of the object under study. Once more we are dealing with a fallacy, according to which ophthalmologists cannot scientifically study other people's eyes because they have eyes themselves $\left.{ }^{6} . c\right)$ The «reflexivity» of social agents, who can take advantage of the explanations provided by sociology and alter their behaviour having them in mind. In this case we are not faced with a triviality, but an important fact: clearly, a quark does not alter its behaviour just because we classify it as a quark, or because we observe it, or explain why and how it moves, while people may do so ${ }^{7}$. What AST does not accept is that this should impede social scientists from studying and explaining this behaviour just as objectively as any other. In fact, if the behaviour caused by sociology itself was a problem for its objectivity, then so would all behaviour, and that would lead us back to one of the fallacious arguments already mentioned, or simply to an arbitrary epistemic nihilism.

\section{Antirrelativism}

It is also frequent in sociology to find a certain variant of epistemic relativism, according to which all discourses, including those of the social sciences, serve some interests of power (Foucault) or exercise some sort of «symbolic violence» (Bourdieu). AST is antirrelativist even in this «sociological» sense: this relativism, like any other, is inconsistent and self-nulifying (Domènech, 2005; Boudon, 2004). Those who affirm that «all discourses are power discourses» or constitute «symbolic violence», and that, for that reason, their validity claims cannot be taken seriously, are in fact inviting us not to take them seriously either. They are telling us that they expect us to accept their thesis not because of the reasons in favour, but because of their position of power, or because of their capacity to exercise "symbolic violence» on us (and notice that, even if that was the case, it would therefore not be very intelligent to say it, since they would be showing their real intentions!). Consider how absurd it is to say things like «I expect to convince you with these reasons that there are no reasons, only power and violence», or "accept my reasoning to show there are no reasons». AST is not impressed in the slightest by views such as these, which insist childishly in ignoring what Wittgenstein called «the harshness of logical obligatoriness».

6. A variant of this argument would be to state that it is impossible for the social scientist to free himself of his ideological prejudices when carrying out his work; I will refer to this in section 2.7., below.

7. Ian Hacking (1999) speaks of «interactive classes» to refer to those classifications that may influence the behaviour of the classified entities. 


\subsection{Unity of science}

\section{The scientific nature of sociology}

For AST, sociology may be, and in part is, a scientific discipline on a par with any other that may be considered as such. Sociology is not literature, nor essay, nor sophisticated journalism, nor socio-political activism, nor a pure and exclusively humanistic discipline like philosophy or art criticism. However, AST does not deny that all these areas can provide valuable and suggestive insights and inspiration for social science; but inspiration only becomes science when it is formulated with due analytical and formal rigour and integrated in an explanatory model ${ }^{8}$. The mission of sociology is not purely descriptive, nor expressive, nor one of social criticism, but basically cognitive: it consists of providing causal explanations of social phenomena with due methodological and formal rigour. Hence, in this fundamental aspect, there are no differences between sociology and other social sciences, nor between these and the natural sciences (Boudon, 2002).

\section{Theoretical unification}

For AST, theoretical integration is a desirable objective. In contrast, the widespread view of sociology as a "wardrobe» from which each can choose the theory or «paradigm» which «suits» him/her best or which he/she feels like "wearing», turns the discipline into a game and a question of taste. This stance fragments sociology and makes any theoretical standpoint unattainable in the eyes of rational criticism. It also leads us to a fruitless dialogue in which «I start from such and such a paradigm or theory» means "nothing that you can say based on another theory affects me at all».

It is truth that, as opposed to other human sciences such as economics or (to some extent) psychology, sociology has never counted on a "paradigm" whose dominance over all others has been institutionalized theoretically and practically to become almost unquestionable. In this way, most sociologists have ended up accepting this «multiparadigmatic» character as an inherent feature of the social sciences, and especially of sociology, and have even regarded it as a desirable or fortunate circumstance. However, one may ask whether this circumstance is inherent in the nature of sociology itself, or is merely a historical consequence of (and therefore contingent on) a particular process of institutionalization. AST argues the latter, and seeks higher degrees of unification, which would enable the discipline to institutionalize procedures of rational argument, criticism, replication of results, evaluation and accumulation of knowledge, which are fundamental for the constitution of any scientific discipline. The opposite view would ultimately entail to accept that meaningful communication among the different versions of social science is impos-

8. Just as Elster has done during his long career with some ideas by all kinds of writers, historians, and essayists (such as Veyne, Sartre, Montaigne, Stendhal, Shakespeare, Racine, etc.). See especially Elster (1983, 1999). 
sible, and this would lead to dissolve sociology into a fragmented set of intellectual approaches with no common denominator. To distinguish between the historical fact of the diversity of "paradigms» and the epistemic value of each of them could well be a step in the right direction.

It is necessary to point out that this position does not imply any type of «intolerance» towards the alleged "pluralism» of sociology. Goldthorpe has rightly recalled Klima's distinction between genuine pluralism and pseudo-pluralism: the first "should be accompanied by a vigorous, indeed often mortal, competition of ideas. Conversely, pseudo-pluralism is characterized by the fact that 'the confrontation of standpoints' is not organized as such a competition, either because rival schools are able to protect themselves against 'foreign' attacks or because their 'approaches' are so formulated as to be largely immune to criticism of any kind» (2000: 7). If there is no «ultimate methodological consensus that determines the ground rules and the standards of achievement according to which the competition of ideas is conducted», then a discipline is not «multiparadigmatic» but rather "pre-paradigmatic» (ibid.). To fight against the pseudo-pluralism that dominates sociology today (against the culture of the "wardrobe») is not intolerance, nor liberticide, nor debate avoidance, but precisely the best way of promoting a really critical and intellectually honest debate, instead of fruitless dialogues designed beforehand to protect oneself from examination by a community of rational agents able to make well-considered judgements.

\section{Integration with the other sciences}

AST argues that sociology should lose its fear of being «invaded» or of «losing its specific character» if it wants to benefit from the contributions and scientific advances coming from other disciplines, and in particular from experimental economics, evolutionary biology, the cognitive sciences, game theory, or modern philosophy of mind. The corporativist purism that leads some sociologists to claim the "autonomy of the social», and to defend it as a city under seige whose alleged "purity" has to be protected from external "contamination", is these days absurd and pretty counterproductive. As Domènech argues, sociology should not «continue forever its isolationist course, entrenched in supposedly pure social facts and impermeable by cosmological facticity»; instead, it «needs to be penetrated by this facticity and to federate itself with the great democratic republic of science» (1998: xviii). When science is conceived as a «democratic republic», there are no frontiers or "particularities» other than those imposed by the conceptual logic of the issues at hand, and by the strength of the arguments provided to deal with such issues.

\subsection{Logical formalization and the use of models}

Intelligibility and logical consistency

AST promotes clarity and intelligibility of discourse, logical consistency, and a precise definition of the terms and concepts used. Hence, it seeks to avoid 
impressionism, intuitionalism, literary pretensions and "subtleties», ambiguity, vagueness, double meanings and puns, lack of systematicity in arguments, and propensity to "suggestion» and "evocation». The ideal rule of scientific discourse is that one says (intelligibly) everything one means, and means everything one says. One of the main definitions of the analytical rigour which characterizes AST has been given by the «analytical Marxist» Gerald Cohen: «I stopped writing in the fashion of a poet who puts down what sounds good to him and who needn't defend his lines (either they resonate with the reader or they don't). Instead, I tried to ask myself, when writing: precisely what does this sentence contribute to the developing exposition or argument, and is it true? You become analytical when you practise that sort of (frequently painful) self-criticism» (Cohen, 1997: 29).

Clarity and intelligibility, contrary to what is often assumed, do not imply a lack of depth. As Van Parijs points out, "clarity [...] does not mean reduction to simplistic positivist clichés, [and it is possible] to be clear without needing to be simple-minded» (Van Parijs, 1981:xiv). The complexity of reality and the nuances that all good science takes into account cannot be used as a charitable alibi to justify certain discourses which are lacking in all rigour, and which often give way to "poker faces» and slogans aimed at convincing oneself or others that, somehow, something has been understood.

As an example of an ambiguous discourse with no informative power whatsoever, but which nevertheless frequently passes for original (and even "critical») «social theory», consider how Foucault tries to define the concept of power:

By power we should understand the multiplicity of power relations which are immanent and inherent to the domain in which they are exercised, and which constitute its organisation; a game which transforms, reinforces, inverts those relations by incessant struggles and fights; [...] the raids, the contradictions which isolate one from another.

[...] Omnipresence of power: not because it has the privilege of regrouping everything under its invincible unity, but because it is being produced every instant, in every part [...]. Power is everywhere.

[...] Power is not an institution, and it is not a structure, it is not certain potency that some are endowed with: it is the name given to a complex strategic situation in a given society (Foucault, 1976: 112-113).

It would be difficult to put down a greater series of imprecisions, truisms, and vague, supposedly clever phrases that could mean just about anything?. Compare the above with the classical definition that Max Weber gave of the same concept:

9. Similar examples are plentiful in the work of «social theorists» such as Luhmann, Bourdieu, Giddens, Alexander, Beck, Bauman, and many "post-modern» and "post-structuralist» authors. For example, regarding Bourdieu, see the definitions of the concept of habitus quoted by Van den Berg (1998) and Hedström (2005: 4), along with their commentaries. 
Power means the probability of imposing one's own will, within a social relationship, even against all resistance and whatever may be the grounds of this probability (Weber, 1922: 43).

The problem of texts like Foucault's, and those of other post-structuralist authors or «social theorists» who write along the same lines, is not that what they say is false or inadequate. The problem (as shown by Sokal and Bricmont, 1998 ) is that it is not possible to know if we are in agreement or not with them simply because they are not intelligible, and therefore cannot be subject to rational criticism. We are dealing with such extremely ambiguous and opaque texts that could mean just about anything. In fact, they seek to avoid any compelling critical reply. On the contrary, a rational discourse open to criticism must be clear and precise enough so that its recipients know exactly how far they disagree with it.

Harry Frankfurt (1986) has analyzed in detail what is bad about this very widespread type of discourse, which he calls bullshit. For the bullshitters, it is not important what they say, but what people think about them. They lack intellectual discipline and meticulousness, show total self-indulgence, do not accept standards, and do not pay attention to detail. Strictly speaking they do not lie, but rather are indifferent to the truth (lying involves knowing the truth and being implicitly committed to it). They do not take what they say seriously. They say things only to see "how they feel» saying them and how others react. Their discourse has no informative content, they are only interested in what «sounds good», without being concerned about how «things really are» ${ }^{10}$. Why do bullshit, conceptual confusion, and unnecessarily dark and pompous discourse have a strong appeal to certain sections of the public and in certain contexts? Of course, I do not attempt here to take on the task of a scientific study in the sociology of knowledge in order to answer that question. Instead, I would like to offer some hypotheses in this respect. I suggest that such kind of discourse $a$ ) may generate an allegedly «fascinating» or "poetical» emotional effect, partly due to its very lack of intelligibility; $b$ ) it garbs itself in the (false) appearance of being «critical» or of "going against the mainstream» (a very popular pose in the social sciences and the humanities) ${ }^{11} ; c$ ) its production

10. Cohen (1997:33), following on from Frankfurt, completes this description: «Bullshit is a form of intellectual dishonesty, and, more particularly, it is the dishonesty of not responding in an honest way to criticism. [...] The bullshitter [...] may be ready to change his position, and he often does so under critical assault. But he does not take proper measure of the force of that assault in order to alter his position in a controlled and scientifically indicated way. He simply shifts to another unthought-through and/or obscure position, in order to remain undefeated (which is the chief thing for a bullshitter)".

11. It is odd to notice, in this sense, the large number of «anti-academics» who make their living precisely in academia (most of them out of public funds) and of «anti-intellectuals» who are comfortably installed in the intellectual world related to the social sciences and the humanities. Would someone understand that anti-militarists were soldiers or that atheists became priests? 
and consumption do not demand technical competences or specialized scientific knowledge, which has to be acquired patiently and as a result of hard work; $d$ ) it offers simple recipes to "globally explain everything» by means of clichés that «sound» vaguely as certain uncontrolled impressions; $e$ ) due to its vagueness and ambiguity, it can be interpreted and used by each and everyone as they like, and anyone can give "their opinion" without the need to make the effort to engage in patient disciplined work to ground it; it often gives rise to an industry of interpreters, commentators, supporters, and note writers for every author; and, finally, $f$ ) due to these and other reasons, there is a growing social demand for this type of discourse.

There are those who will still question the demand for intelligibility by stating that total precision and clarity are impossible, and that there is always a margin for ambiguity. However, this claim would be as absurd as saying there is no sense in learning a language because we will never reach perfection in its use, or that it is not worth to treat myopia since we will never achieve a perfect vision.

\section{Formalization and the use of models}

AST frequently uses formal models and argues for taking the formalization of scientific-social discourse as far as it is possible and reasonable considering the objectives of the investigation. Formalization and the use of models offer many advantages: $a$ ) They favour parsimony and intellectual economy (the application of «Ockham's razor»). b) They promote exhaustive and systematic exploration of possibilities and implications. $c$ ) They eliminate ambiguities and fix the meaning of terms, thus saving time and energy spent in resolving misunderstandings and inexact interpretations, as well as facilitating communication and relevant criticism (instead of the fruitless dialogues which, as said above, are all too frequent in sociology). d) They allow the accumulation of knowledge and make possible to replicate results. And $e$ ) they make our assumptions explicit; otherwise they tend to remain hidden even from the researcher himself. Formalization and use of models establish clear «rules of the game», avoiding the impressionism and intuitionalism that is so prevalent in sociology.

The traditional rejection of formalization and models by sociologists is due, in most cases, to one of the following prejudices: 1) The prejudice that sociology "commits violence» on reality if it tries to study it with formal models. This is no more than another version of the fallacy (used by Adorno against Popper in the famous "dispute over positivism»; see Adorno, 1969) according to which the nature of research methods should coincide with that of their object, as if the chemical analysis of soup should taste of soup ${ }^{12}$. 2) The prejudice that the use of formal models is "bad» because they "simplify» reality. Obviously they do so, and to suppose that any scientific work can avoid some degree of simplifi-

12. Obviously, there are criteria of relevance in scientific methodology to choose one research method or another in each specific piece of investigation, but this has nothing to do with claiming an «intrinsic quality» of the object (in this case of social reality) which impedes a priori its study with formalized models, as is put forward by the prejudice under discussion. 
cation is to confuse the map with the territory. The question is not about whether we should use «simplifying» models or not, but which models and which degree of simplification will be sufficient and relevant to discover what we want to know. The debate about the realism of the assumptions behind many models (for example, those of rational choice theory) often incurs in this confusion. This does not mean that AST does not consider the assumptions of some traditional models as excessively simplistic and seeks to enrich them by means of empirical evidence (see for example, the articles by Gintis, Abell or Hedström included in this issue). 3) The prejudice that models are "ahistorical». As a general rule, this is simply false, since there are evolutionary models that seek to explain historical facts and developments, and since any type of historical-contextual condition may be included as an assumption of a model. Once again, if «isolating» or «abstracting» certain features from reality means that we are being «ahistorical», then any study of reality will be so. 4) The prejudice that formalization necessarily ends up becoming a goal in itself. This is also false, for AST considers as a trivial fact that formal models are instruments of scientific explanation, and not ends in themselves. Formal models should be used as long as they save work and increase explanatory power compared with other methodological options. AST does not consider it desirable to go further than what is reasonable in terms of formalization, but neither that we should accept a lower level of formal rigour than it is possible or advantageous in social science, nor that we should fall into the trap of «sour grapes» (as we cannot or do not know how to use a formal model, we conclude that it is not desirable to do so).

In short, the construction and application of models help us to avoid what Elster calls the second "law of pseudoscience», which says "that every thing is connected causally with every other, an idea that causes resistance to analytical modelization because it is inevitable that we abstract some of the causally relevant features of the situation to understand the role of the most important aspects» (2001: 18n).

\subsection{Reductionism}

AST usually considers reductionism as a virtue of scientific theories, and not, as often happens in sociology, as a pejorative label which can be used to discredit a certain point of view (Elster, 1982, 1989; Boudon, 1998; Hedström, 2005; Noguera, 2003). Rejecting reduction as an aim of a scientific discipline is like accepting that there are "ontological gaps» in reality, and that certain phenomena can be self-caused or appear from nothing ${ }^{13}$.

Nevertheless, and surprisingly, many sociologists still think that reductionism, if accepted, implies a serious danger for the existence of sociology (and, therefore, for their jobs). Such thinking comes from the confusion of reductionism with eliminationism. For AST, macrosocial phenomena are reducible

13. Recall what was said in section 2.2 (above) on the integration of scientific disciplines. 
to microphenomena, but some of their properties may have a causal and noneliminable role of their own at a level of analysis which is relevant to sociology. Without this reduction to microphenomena, however, we cannot count on an intelligible explanation of these macrophenomena. Notice that all other scientific disciplines operate with similar suppositions. If the fears of some sociologists regarding reductionism were justified, chemists and biologists would long ago have lost their jobs, and there would only be physicists specialized in the study of fundamental particles.

All that reductionism states is that a macrophenomenon is caused by the interaction of microphenomena, although (and this is the difference from eliminationism) it assumes that the properties of the latter do not have to coincide mechanically with the properties of the former (in the same way that the properties of water do not coincide with those of oxygen and hydrogen taken separately, although water can be reduced to them). Many hasty uses of the concept of "emergency" and "complexity» in social sciences ignore the above and hide the absence of an intelligible explanation of the appearance of such macrophenomena and their properties (Van Parijs, 1981; Hedström, 2005). The same happens with many clichés which are repeated ad nauseum such as "the whole is more than the sum of the parts». If this vague assertion implies there is something in the whole which is irreducible to the interaction of its parts and their causal effect, then we are dealing with a metaphysical claim that conceals a «divine hand» (or any similar «supernatural» factor) at some level of reality. And if it does not imply this, then it is clearly compatible with reductionism. Phrases and words such as those aforementioned, nevertheless, are often used in sociology as talismans or mystic amulets to avoid the meticulous and hard work of seeking intelligible explanations of social phenomena.

\subsection{Causal explanation}

One of the fundamental principles of AST is that the aim of sociology is the causal explanation of social phenomena. This may seem obvious, but as Boudon (2002) shows, most of what is given the name of «sociology» does not have primarily this cognitive function. Instead, it is expressive sociology (which seeks to cause certain emotions or impressions by means of narrating the quasi-literary subjective experiences of the social agents or the sociologists themselves), informative sociology (which merely describes certain social phenomena or accumulates data), or critical sociology (which denounces and criticizes certain states of the social world from a normative or ethical-political point of view). In contrast, cognitive sociology, as defended by AST, seeks to explain in detail enigmatic social phenomena by means of the construction of formal theories that specify intelligible causal mechanisms, thus providing microfoundations for the explanation. For AST, explaining is not describing, nor establishing taxonomies or typologies of phenomena (Hedström, 2005: 12ss), nor engaging in sophisticated journalism, nor "empathising» with social actors or referring in a literary manner to social reality. As Van Parijs (1981:3) notes, 
paying attention to the morphology of explanation is the only way of revealing the deep structure of social science, which unifies all its tasks through different disciplines or theoretical schools.

Two remarks should be made in this respect. First, the so-called «interpretivist» or "hermeneutic» sociologists have often tried to differentiate between the "causal explanation» of social phenomena and their «understanding». For AST, however, both things have no sense as different methods. As Max Weber (1922: 6-12) pointed out, «understanding» the meaning the actions have for the agents is part of the causal explanation of these actions. To "understand" is nothing less than attributing mental states with a certain propositional content on the part of the individuals. Therefore, AST shares the classical point of view set out by Davidson, according to which the reasons that individuals have for acting as they do can be legitimately understood as causes of their action, giving rise to intentional explanations (Davidson, 1963; Elster, 1983; Boudon, 2003). Hedström, for his part, speaks of $D B O$ theory, that is, the theory that explains actions as being caused by individuals' desires (D), beliefs (B), and opportunities $(\mathrm{O})$. However, it is still frequent to hear some sociologists say things so inconsistent as «I don't want to discover the causes of this phenomenon or action, I just want to understand it». But any attempt to «understand» the actions of an agent necessarily involves some causal model or assumption; the real choice is between making it explicit as such, or leaving it in the limbo of the unthought and vague.

Second, AST often claims that a valid explanation "predicts» the occurrence of certain events. In this respect, it is necessary to dispel a common confusion among sociologists: "prediction" does not necessarily refer here to an event in the future, but rather to the establishment of a causal link between an event and its expected effect. A causal model which tries to explain why the Stock Exchange crisis of 1929 happened "predicts» certain behaviour although this took place over seven decades ago.

\subsection{Social mechanisms: the microfoundations of explanation}

Explaining is to provide patterns of intelligibility (Van Parijs, 1981). Hence, a requirement for satisfactorily explaining a phenomenon is to specify its microfoundations (Elster, 1982, 1989). In the case of social phenomena, AST seeks to specify the social mechanisms that underlie them. According to Hedström (2005:2), "the core idea behind the mechanism approach is that we explain a social phenomenon by referring to a constellation of entities and activities, typically actors and their actions, that are linked to one another in such a way that they regularly bring about the kind of phenomenon we want to explain». Explanation based on mechanisms avoids both the nomological model of the covering law, and also mere statistical association ${ }^{14}$.

14. See the articles by Barbera, Hedström and Lizón, in this issue. Cf. also Hedström and Swedberg (1998). 
Specifying the social mechanisms that cause phenomena avoids pseudoexplanations that rely on «black boxes» (many of which refer to vague entities and processes such as «socialization», «culture», "values», etc.; cf. Boudon, 1998). It also excludes the postulation of any sort of sui generis causality or logic (different from the conventional one) such as "dialectics», «structural homology», non-intentional "meanings», «reasons» without agent, or "objective» teleologies (Elster, 1982, 1983). Finally, it rules out the confusion between "explaining» and "naming» or "labelling» phenomena (something that authors like Bourdieu, Giddens, Beck, Habermas and others are fond of; see Van den Berg, 1998). For AST, sociology should learn to accept that social phenomena may be explained causally (in the conventional sense of specifying a mechanism that connects two events), but not «understood» according to an alleged «deep meaning» that goes beyond this ordinary causality or the meanings that are intentionally projected by human beings.

As Barbera remarks (2004), another advantage of explanations by means of mechanisms is that they are open to empirical testing ${ }^{15}$. The best way of distinguishing a scientific theory from a pseudo-theory, a dogma, or an ideology is that the latter are able to reinterpret any imaginable event according to their principles, while the former cannot ${ }^{16}$. A theory has informative power, and is therefore open to empirical testing insofar as it excludes possible worlds.

\subsection{Axiological neutrality}

\section{Differentiation between judgements based on fact and normative judgements} There is no doubt that in the social sciences normative concerns are often linked to cognitive ones. Nevertheless AST, with its emphasis on formal models and the specification of causal mechanisms, offers an unbeatable basis for analytical differentiation between judgements of fact and value judgements in everyday scientific practice. As was already said, AST promotes a cognitive sociology, not a sociology focused on social criticism (which does not mean that many analytical sociologists do not view such criticism in a good light or are not openly critical themselves).

\section{Ideological vs. epistemic points of view}

There is an urgent need to do away with a mystic-essentialist prejudice (quite widespread in sociology) according to which adopting a conventional analytical or scientific perspective implies necessarily something like «justifying or legitimizing the status quo» or a certain political «conservatism». This prejudice is based on the confusion between political ideology and gnoseological

15. One may see just how far the contributors to this issue consider as natural something that has given rise to rivers of ink in sociology under the unwieldy and grandiloquent label of «integration of theory and empirical research».

16. Once again, it is still possible to meet sociologists who believe that this capacity to cater for any possible event is a virtue for a «theory». 
instruments. Fortunately, more and more sociologists and social scientists do not see this to be such a necessary link between both things. One can work with AST when trying to know social reality with extremely different goals: to conserve this reality, to transform it in one direction or another, to obtain academic prestige, to get a job, because of rational conviction, out of pure curiosity, to be loyal to a tradition, or even to flirt with someone (or for any other combination of these). But none of those possible motives has anything to do with the epistemic value of AST since, as Pareto well knew, truth and utility are very different things. The existence of an "analytical Marxism», for example, destroys any pretension that AST is «essentially» conservative. And as Marx himself well knew, those who want social change would do well to take as a basis of their actions a good scientific theory on how this comes about and on the reality which they wish to change, instead of falling into the confusion between epistemic point of view and political ideology. Vague and confused ideas with a weak empirical support from social reality, despite how much they may motivate human beings, will be counter-productive if they are taken as a basis for bringing about social changes. Conversely, it is precisely good cognitive and explanatory sociology that may be successfully used by conservatives in order to keep things as they are, or by radicals in order to change them.

\section{Ideology vs. technical instrument}

A variant of the abovementioned prejudice associates the use of certain research techniques with certain value or even ideological options (cf., for example, Bourdieu et al, 1968; Bourdieu and Wacquant, 1992). On the contrary, AST considers, like the analytical marxist Gerald Cohen, that «the commitment to the techniques [...] reflects nothing less than a commitment to reason itself; [...] to argue that there is something hopelessly undialectical or individualist about analytical techniques themselves, represents, we believe, an unwillingness to accept the rigour of reason» (Cohen, 1997: 30-31).

\section{Antipositivism}

A very frequent accusation in sociology, which is often aimed at AST, is that of "positivism». It would seem that in the social sciences such an accusation, if it were true, would automatically disqualify a claim or a whole approach. However, leaving aside the fact that those who use it never actually define precisely what they understand by "positivism", its application to AST can only be based on misinformation and intellectual idleness. In fact, AST is an openly antipositivist approach to social science ${ }^{17}$ : it incorporates processes which are not directly observable (such as mental states), it argues for explanations based on mechanisms rather than nomological laws or statistical associations, and it does not show any explicit intention of «technocratic» social reform.

17. As the articles by Barbera and Lizón, in this issue, argue. 


\subsection{Actionalism, intentionalism, rationalism}

The explanation by means of mechanisms, which AST defends, is typically based on individuals' actions, and preferably on their intentional actions (Van Parijs, 1981). The abovementioned DBO theory may be put this way: "Individuals act; they are not merely pushed around by anonymous social forces; and in order for a theory to be explanatory it must consider the reasons why individuals act as they do" (Hedström, 2005: 36-37). Sociological explanation «should avoid the 'atomized' and 'heroic' assumptions of traditional economics as well as the 'causalism' of traditional sociology» (ibid.).

As the above quote shows, along with the central role of actions and intentions, AST also gives an explicit fundamental role to rationality (Boudon, 2003). The reasons agents have to act, and not only blind forces or irrational intentions (instincts, impulses, inertia, or similar), are often causes of their actions. When individuals believe that they have "good reasons» to act in a particular way, these reasons are the most plausible explanation for their action (and the beliefs and desires that form these reasons may, in turn, have been formed on the basis of reasons: this is what is stated by Boudon's theory of cognitive rationality).

The advantage of this point of view, apart from its plausibility in phenomenological and common sense terms, is that rational action is its own explanation (be it cognitively or instrumentally). As Weber well knew, irrationality or resort to "hidden» forces use to lead to pseudo-explanations, or just be the implicit recognition of the inability to explain an action. Irrationality on the part of agents should only be assumed when we have run out of all other possible rational explanations for their action (this is what is claimed by the «charity principle» for which Davidson has argued compellingly; see Davidson, 1984). For this reason, AST mistrusts «culturalist» or "sociologistic» explanations that do not specify understandable psychological mechanisms to account for actions: this is the case of pseudo-explanations of the «black box" type that affirm that "X carried out action Y because he is a member of society $S$ or culture $C$ », or «because he has been socialized in the tradition $T$ », or «because he has the cultural identity $\mathrm{I}^{1}{ }^{18}$.

To conclude, it may be important to add precision to what has been said: a) AST's rationalism subverts the traditional idea (assumed by classical sociologists as different as Pareto and Parsons) that sociology studies non-rational (or «non-logical») actions, while economists study rational ones. There is no epistemic or methodological reason to establish this «division of labour»; on the contrary, there are many reasons not to. b) AST does not usually accept the «standard" version of rational choice theory (as it is used, for example, in neo-classical economics), but rather softens some of its assumptions and enriches

18. See, in this respect, the excellent work by Aguiar and De Francisco (2003), in which they offer an analytical reduction of the nebulous (and so abusively used in sociology) concept of «identity». 
such version with empirical results from experimental psychology and economics (see Gintis' article in this issue) and with wide concepts of rationality which go beyond the purely instrumental one (see Elster, 1983; Boudon, 2003). c) AST assumes, therefore, a motivational pluralism on the part of individuals (who may be selfish, altruistic, or both things in different degrees depending on the action context) without giving up its preference for rationality as a general motivational assumption. d) AST's intentionalism and rationalism do not imply that social phenomena respond to an intentional design on the part of some agents. On the contrary, AST shows how these phenomena are often the unintentional and unexpected result of many intentional actions. e) Obviously AST also admits (and in fact uses profusely) other explanatory instances apart from rationality, mainly social norms and evolutionary mechanisms of selection and reinforcement (Van Parijs, 1981; Elster, 1989; see Gintis, in this issue).

\section{The articles in this issue}

The current issue of Papers aims at offering a significant and representative (although obviously incomplete) sample of the contemporary work that is being developed in the spirit of AST. In the following lines, I offer a brief commentary of the texts that the reader will find in this volume.

Filippo Barbera's article represents a truly informative and complete introduction to the basic achievements, authors, and aims of AST. Barbera explains clearly the dividing lines between AST and other ways of conducting social science, introduces its main authors and their contributions, and looks in depth at the concept of explanation by means of social mechanisms. His essay is, without doubt, a very valuable introduction to AST. At a higher level of abstraction, John R. Searle, a well known and prestigious philosopher of mind and language, sets out his influential and original point of view on social ontology. His proposal, as anyone who has read The Construction of Social Reality (1995) knows, offers for the first time a plausible and intelligible ontology for social science. Searle's ontology seeks to connect social science with the rest of the scientific disciplines without ontological gaps, and avoids the antinomies of "constructionist" and antirealist views that have become so widespread in recent years in the social sciences and the humanities. The interest of his article lies, above all, in the examination and further development of some ideas introduced in the aforementioned book.

Peter Hedström, one of the leading current supporters of AST, insists in the usefulness of the explanation by means of social mechanisms. He offers an informative typology of those mechanisms and shows how this perspective can be used for the explanation of social outcomes and social change departing from the individual level. To this end, Hedström uses the innovative technique of empirically calibrated and agent-based simulation models. On the same lines, Sandra González, one of the young talents working in AST, also uses multi-agent simulation techniques to show the role of social networks in the creation and maintenance of social capital, as well as their implications for 
political participation. Both articles are excellent examples of the potential of AST and social simulation models to test the plausibility of the assumptions behind sociological theories. They also show the informative power, rigour, and precision that social science may achieve when it takes itself seriously.

The articles by Herbert Gintis and Peter Abell cover, from complementary standpoints, a key subject for AST: the unification of social and human behavioural sciences. Gintis' article examines how advances in (interculturally tested) experimental game theory and cognitive-evolutionary sciences can lead us to think of a unified model that explains human behaviour. For his part, Abell displays a unified framework for economics and sociology, based on a «soft» version of rational choice theory combined with an analytical vision of social interaction, and using, as does Gintis, evolutionary game theory. Both works show how, far from fearing «invasion" and «imperialism", sociology can only gain from this type of unifying focus. And they point out that experimentation techniques, traditionally overlooked by sociology, are a promising step in this direction.

Raymond Boudon, an undisputed classic in the field of AST, also centres his contribution on the problem of how to articulate a general theory of human behaviour and argues for overcoming both the standard theory of rational choice and the "causal» theories (traditionally used in sociology) which turn agents into «irrational idiots», to move on to a model without «black boxes» and based on contemporary cognitive science: this is his theory of cognitive rationality (which includes a theory of axiological rationality). This theory not only seeks to explain actions, but also the origin and formation of the beliefs and values on which they are based.

Germán Loewe takes up the question of experimental techniques to offer an overview of one of the most interesting and innovative research fields in behavioural science: the theory of intertemporal choice. His article provides a perfect example of how an advanced social science can help the theory of rationality to challenge with rigour some of its core assumptions, without giving up a high level of formalization and empirical testing (very differently from the misinformed discourses that often pass in sociology as "criticisms» of rational choice theories). This work is also a healthy call to make assumptions explicit by means of formalization.

Jordi Mundó illustrates with his work another of the most recent vanguard fields of behavioural research: evolutionary psychology and biology. Mundó delivers some compelling and informed arguments that sociologists cannot ignore unless they suffer from dogmatism, obscurantism, or intellectual idleness. His main argument challenges the existence of a radical gap between nature and society - a belief that has been common in the social sciences (and that brings with it the corollary of the infinite malleability of human beings by culture). On the contrary, Mundó argues that there are biological or psychological constrictions on cultural variability, which are the result of evolutionary mechanisms of selection that operated on the beginnings of human development. Once again, we are faced with a healthy invitation to stop seeing 
sociology as an autarkic discipline, isolated from the epistemic continuum in which the contemporary sciences thrive.

Lastly, and as an excellent end to the issue, Ángeles Lizón's article is written from a historical perspective which does not ignore systematic and substantive aspects. She offers us a mature and exhaustive review of the relations between causal explanation and statistical techniques in 20th century sociology. Lizón provides solid arguments in favour of AST and the social mechanisms approach, and against pseudo-explanations based on the so-called «variable perspective» or on statistical associations as such. Her work is a necessary warning against the fetishism of technique as an end in itself and against ignoring the morphology of causal explanation - and shows that it is not precisely AST that makes such mistakes.

In short, I am confident that the following articles (along with the selection of bibliographical notes that is presented) contribute to answering clearly the question posed in the title of this introduction: yes, we do need an Analytical Sociological Theory; and yes, such a theory does exist and it is well furnished with epistemic, methodological, and technical instruments to lead the way for the consolidation of sociology as a scientific discipline federated along with the other contemporary sciences, and to relegate to oblivion the Peter-Pan-like adolescence that it has suffered from for too long. The many social scientists who have been carrying out rigorous scientific work for many years can only be too glad that AST may help sociology to become more aware of such work.

\section{Acknowledgements}

This issue would not have been possible without the support from the very beginning of the editor of Papers, Carlota Solé, nor without the efficient work of Judit Caballero. I would like to thank also all the authors who have contributed to it (including those in the bibliographical notes) for their kindness, dedication, and availability. Additionally, the original idea of publishing this volume and the contents of this introduction owe much to the monthly discussions which have taken place in Barcelona, since January 2003, in the Analytical Social Theory group, whose members I want to thank for their enthusiasm and never-ending intellectual stimulation: they are Alex Boso, David Casassas, Elsa Corominas, Mauricio García, Sandra González, Irkus Larrinaga, Germán Loewe, F. J. Miguel Quesada, Mihaela Vancea, Camila Vollenweider and Ernest Weikert.

\section{Basic and introductory texts on Analytical Sociological Theory}

ABELL, Peter (1988). The Syntax of Social Life. Oxford: Oxford University Press. BARBERA, Filippo (2004). Meccanismi sociali. Elementi di sociologia analitica. Bologna: Il Mulino.

BoudON, Raymond (2003). Raison, bonnes raisons. Paris: PUF.

Coleman, James (1990). Foundations of Social Theory. Cambridge: The Belknap Press. 
ElSTER, Jon (1989). Nuts and Bolts for the Social Sciences. Cambridge: Cambridge University Press. [Spanish edition: Tuercas y tornillos. Una introducción a los conceptos básicos de las ciencias sociales. Barcelona, Gedisa, 1991.

GoldTHORPE, John H. (2000). On Sociology. Numbers, Narratives and the Integration of Research and Theory. Oxford: Oxford University Press.

Hedström, Peter; Swedberg, Richard (eds.) (1998). Social Mechanisms. An Analytical Approach to Social Theory. Cambridge: Cambridge University Press.

Hedström, Peter (2005). Dissecting the Social. On the Principles of Analytical Sociology. Cambridge: Cambridge University Press.

\section{References}

ABELl, Peter; ReYNIERS, Diane (2000). «On the failure of social theory». British Journal of Sociology, vol. 54, no 4 (December), p. 739-750.

Adorno, Theodor W. (ed.) (1969). The Positivist Dispute in German Sociology. London: Heinemann, 1976.

AgUiar, Fernando; De Francisco, Andrés (2003). «Identidad, normas e intereses». Revista Española de Investigaciones Sociológicas, $\mathrm{n}^{\circ} 103$ (October-December), p. 9-27.

BARBERA, Filippo (2004). Meccanismi sociali. Elementi di sociologia analitica. Bologna: Il Mulino.

BOUDON, Raymond (1998). «Social mechanisms without black boxes». In: Hedström, P.; Swedberd, R. (eds.). Social mechanisms. An Analytical Approach to Social Theory. New York: Cambridge University Press.

- (2002). «Sociology that Really Matters». European Sociological Review, vol. 18, $\mathrm{n}^{\circ}$ 3, p. 371-378. (Spanish version: «La sociología que realmente importa», Papers. Revista de Sociologia, no 72, 2004, p. 215-226).

- (2003). Raison, bonnes raisons. Paris: PUF.

- (2004). The Poverty of Relativism. Oxford: The Bardwell Press.

BouRdieu, Pierre; WACQUANT, Loïc J.D. (1992). An Invitation to Reflexive Sociology. Chicago: Chicago University Press.

Bourdieu, Pierre; Chamboredon, Jean-Claude; PAsseron, Jean-Claude (1968). Le métier de sociologue. Paris: Mouton.

COHEN, Gerald A. (1997). «Commitment Without Reverence: Reflections on Analytical Marxism». Imprints: a journal of analytical socialism, vol.1, no3 (March).

D’Agostini, Franca (1997). Analiticos y continentales. Guía de la filosofía de los uiltimos 30 años. Madrid: Cátedra, 2000.

DAVIDSON, Donald (1963). «Actions, Reasons and Causes». In: Essays on Actions and Events. Oxford: Oxford University Press, 1980.

- (1984). Inquiries into Truth and Interpretation. Oxford: Clarendon Press.

DOMÈNECH, Antoni (1998). «Prólogo a la edición española». In: Hollis, Martin. Filosofia de las ciencias sociales. Barcelona: Ariel.

- (2005). «El eterno retorno de Calicles». In: Estany, Anna (ed.). Filosofía de las ciencias naturales, sociales y matemáticas. Madrid: Trotta.

ELSTER, Jon (1982). «Marxism, functionalism and game theory». Theory and Society, vol.11, p. 453-482.

- (1983). Sour Grapes. Studies in the Subversion of Rationality. Cambridge: Cambridge University Press.

- (1989). Nuts and Bolts for the Social Sciences. Cambridge: Cambridge University Press. 
- (1999). Alchemies of the Mind. Rationality and the Emotions. Cambridge: Cambridge University Press.

- (2001). Sobre las pasiones: emoción, adicción y conducta humana. Barcelona: Paidós. Foucault, Michel (1976). Historia de la sexualidad. Vol. 1: La voluntad de saber. Madrid: Siglo XXI, 1995.

FRANKFURT, Harry G. (1986). «On Bullshit». In: The importance of what we care about. Cambridge: Cambridge University Press, 1997.

GoldTHORPE, John H. (2000). On Sociology. Numbers, Narratives and the Integration of Research and Theory. Oxford: Oxford University Press.

HaCKING, Ian (1999). The Social Construction of What? Cambridge (Mass.): Harvard University Press.

Hedström, Peter (2005). Dissecting the Social. On the Principles of Analytical Sociology. Cambridge: Cambridge University Press.

Hedström, Peter; SwedberG, Richard (1998). «Social Mechanisms: An Introductory Essay». In: Hedström, Peter; SwedberG, Richard (eds.). Social Mechanisms. An Analytical Approach to Social Theory. Cambridge: Cambridge University Press.

- (eds.) (1998). Social Mechanisms. An Analytical Approach to Social Theory. Cambridge: Cambridge University Press.

Noguera, José A. (2003). «¿Quién teme al individualismo metodológico? Un análisis de sus implicaciones para la teoría social». Papers. Revista de Sociología, no 69, p. 101-132.

POPPER, Karl (1940). «What Is Dialectics?». In: Conjectures and Refutations. London: Routledge \& Kegan Paul, 1974.

SARTORI, Giovanni (1984). «Guidelines for Concept Analysis». In: SARTORI, Giovanni (ed.). Social Science Concepts: A Systematic Analysis. Beverly Hills (California): Sage. SeArle, John R. (1995). The Construction of Social Reality. New York: The Free Press. SOKAL, Alan; BricmONT, Jean (1998). Intellectual impostures. London: Profile Books. VAN DEN BERG, Axel (1998). «Is Sociological Theory Too Grand for Social Mechanisms?». In: HEDSTRÖM, Peter; SwEDBERG, Richard (eds.). Social Mechanisms. An Analytical Approach to Social Theory. Cambridge: Cambridge University Press.

VAN PARIJS, Philippe (1981). Evolutionary Explanation in the Social Sciences. Totowa (New Jersey): Rowman \& Littlefield.

Weber, Max (1922). Economía y sociedad. Esbozo de sociología comprensiva. México: Fondo de Cultura Económica, 1964. 